\title{
Application of Desert Date (Balanites aegyptiaca) Seed Oil as Potential Raw Material in the Formulation of Soap and Lotion
}

\author{
Charity Uren Zang1, Alexander Asanja Jock ${ }^{1 *}$, Hassan Ibrahim Garba², \\ Yarkasuwa Istifanus Chindo ${ }^{2}$ \\ ${ }^{1}$ Chemical \& Petroleum Techniques, Department of Science Laboratory Technology, University of Jos, Jos, Nigeria \\ ${ }^{2}$ Department of Chemistry, Abubakar Tafawa Balewa University, Bauchi, Nigeria \\ Email:*alsanja@gmail.com
}

How to cite this paper: Zang, C.U., Jock, A.A., Garba, H.I. and Chindo, Y.I. (2018) Application of Desert Date (Balanites aegyptiaca) Seed Oil as Potential Raw Material in the Formulation of Soap and Lotion. American Journal of Analytical Chemistry, 9, 423-437.

https://doi.org/10.4236/ajac.2018.99033

\section{Received: July 30, 2018}

Accepted: September 17, 2018

Published: September 20, 2018

Copyright (c) 2018 by authors and Scientific Research Publishing Inc. This work is licensed under the Creative Commons Attribution International License (CC BY 4.0).

http://creativecommons.org/licenses/by/4.0/

c. $\underset{\mathrm{EY}}{\mathrm{i}}$ Open Access

\begin{abstract}
Balanites aegyptiaca has multiplicity of uses and almost every part of the plant is useful including its flowers, leaves, bark, root and fruit. In this study, oil from Desert date (Balanites aegyptiaca) kernel seed was extracted, analyzed and used in the formulation of soap and lotion. The physical parameters determined were oil content, specific gravity, refractive index and moisture content. These were found to be $45.32 \% \pm 0.0026 \%, 0.90 \pm 0.03,1.45 \%$ and $0.114 \% \pm 0.04 \%$, respectively. The chemical parameters evaluated include saponification value $(200.02 \pm 0.12 \mathrm{mg} \mathrm{KOH} / \mathrm{g})$, acid value $(2.14 \pm 0.28 \mathrm{mg}$ $\mathrm{KOH} / \mathrm{g})$, iodine value $(104.39 \pm 0.00 \mathrm{100} / \mathrm{g})$, peroxide value $(2.95 \pm 0.00$ $\mathrm{mEq} / \mathrm{kg})$ and free fatty acid $(0.82 \% \pm 0.01 \%)$. The oil quality assessments test indicates \%FFA content of $0.84 \%$ and the fatty acids composition of the oil was evaluated using GC-MS as FAME; the oil contains about $47.52 \%$ unsaturated fatty acids. The seed kernel of Balanites aegyptiaca is a good source of vegetable oil. Soap formulated from the oil is considered a good soap based on the soap quality parameters determined. Lotion formulated has a good stability when subjected to lotion stability test.
\end{abstract}

\section{Keywords}

Balanites aegyptiaca, Oil, Formulation, Soap

\section{Introduction}

Balanites aegyptiaca is used for firewood, charcoal, poles, timber, utensils, tool handle, food, fodder [1], mulch, shade, windbreak and gum [2]. The plant may be grown for its fiber, oil and for medicinal values; it is also used in treatment of 
several diseases and disorders since ages. Balanites aegyptiaca seed kernel oil falls in the group of such oils termed as vegetable oils since it is extracted from a plant source. The chief importance of vegetable oils lies in their food value [3]. The seed kernel is considered as an extremely useful edible product, it is rich in oil, protein, minerals and it has been reported to be used for over thousands of years [4].

Oils are heterogeneous biochemical substances which have in common, the property of being soluble in most organic polar solvents (chloroform, benzene, diethyl ether, etc.) and insoluble in water [5]. The term lipid is the scientific name for fatty acids and similar chemicals often found in oils produced by living things. They may contain diethyl-glycerol, free fatty acids, phosphatides, sterols and fat-soluble vitamins like tocopherol, pigments, waxes and fatty alcohol are present but as minor components [6]. Oils may be sourced from animal, vegetables or petrochemicals [7]. All oils and fats are made up of a mixture of these triglycerides [8]. The character of a particular oil or fat depends on the actual fatty acids present in the individual triglyceride molecules. Some of these fatty acids have longer carbon chains than others and exist as saturated, mono-unsaturated or polyunsaturated fatty acids. Fats are chiefly made up of saturated fatty acids while oils are chiefly made up of unsaturated fatty acids. Although many different parts of plants may yield oil, in commercial practice, oil is extracted primarily from seeds of plants which grow in many different parts of the world [9]. The commonest fats and oils are obtained from various domesticated plants and animals. They are important in food industries, Oleo-chemical industries and in other industries.

The largest vegetable oil sources are the oil seed crops of soya bean, rape seed, sun flower and cotton seed. These are grown in tropical or warm climates as well as temperate climates [10]. Many compounds in oil seeds have proven nutritional benefits with great possibilities for using them to develop new functional vegetable oils. Vegetable oils are now available with improved levels of vitamin $\mathrm{E}$ and phytosterols (Sterols derived from plants). They are present in all plants and in food products of plant origin. Vegetable oils are the richest natural sources of phytosterols. Among the vegetable oils, corn and rapeseed contain the highest amounts of phytosterols [8]. Vegetable oils are very important ingredient in many manufactured products; it acts as emulsifiers, lubricants, plasticizers, surfactants, plastics solvents and resins.

Soaps are compounds that consist of long chain of hydrocarbons attached with a carboxylic acid which is ironically bonded to the metal ion usually sodium or potassium, it is a combination of animal fat or plant oil with caustic soda. Soaps are therefore called the salts of fatty acids which are usually used as surfactants for washing, bathing and cleaning [11]. Soaps are obtained by the treatment of vegetable oils or animal fats with a strong alkaline solution. The three molecules of fatty acids in the triglyceride gets attached to a single molecule of glycerol and results in a chemical reaction termed saponification [12]. Soaps are used on a day to day basis in households and their physicochemical properties 
will be determined its quality, efficiency and cleaning properties [13]. Lotions are low to heavy viscosity topical substances that are intended for application to unbroken skin. They are formulated not as medicines but simply to smoothen, moisturize and soften the skin. Most lotions are oil in water although water in oil formulations is also possible. The key components of a skin care lotion, cream or gel emulsion are the aqueous and oily phases [14].

Balanites aegyptiaca seed kernel is readily available in northern Nigeria and the use of the seed is not popular in areas where it is produced. This research attempts to use the seed kernel oil of Balanites aegyptiaca as a good raw material for the production of soap and body lotion.

\section{Materials and Methods}

\subsection{Oil Characterization}

The dried seeds of Balanites aegyptiaca (100 kg) were purchased from vendors at Kwararafa market in Jos, Plateau State-Nigeria. The sample was spread under shade and sorted to remove unwanted materials. The seeds were manually crushed to remove the seed kernel from the husk shell and the kernel was then milled into powder using a ball mill.

The fresh seed kernel oil of Balanites aegyptiaca was extracted by both solvent and mechanical methods. The solvent extraction was done using soxhlets apparatus and petroleum ether as the solvent. The milled seed kernel $(200 \mathrm{~g})$ was packed in the thimble; $250 \mathrm{ml}$ of petroleum ether (boiling point $60^{\circ} \mathrm{C}-80^{\circ} \mathrm{C}$ ) was transferred into a $500 \mathrm{ml}$ round bottom flask which was place on a heating mantle and temperature maintained at $80^{\circ} \mathrm{C}$. The entire set-up was allowed for continuous extraction for $8 \mathrm{hrs}$. After exhaustive extraction the content of the round bottom flask was transferred into a quick fit flask of a rotary evaporator and oil separated from the solvent.

\subsubsection{Moisture Content of Oil}

The moisture content was determined according to [15]. A clean dried Petri dish was weighed and $5 \mathrm{~g}$ of the sample was placed in it. It was then placed in the oven at $105^{\circ} \mathrm{C}$ for $24 \mathrm{hrs}$. This also was done in triplicate after which the average was calculated.

$$
\% \text { Moisture }=\frac{W_{1}-W_{2}}{W_{1}} \times 100
$$

where

$$
\begin{aligned}
& W_{1}=\text { Weight of sample before drying. } \\
& W_{2}=\text { Weight of sample after drying. }
\end{aligned}
$$

\subsubsection{Refractive Index}

The refractive index of the oil sample was also determined according to the method prescribed [16]. The refractometer was connected to a thermostatically controlled water bath that maintained the temperature of the refractometer at 
$40^{\circ} \mathrm{C}$. The oil sample was spotted onto the slide of the refractometer and viewed by rotating the knobs while the refractive index was recorded.

\subsubsection{Specific Gravity}

The specific gravity of the oil was determined by conventional method. The oil was vacuum filtered to remove any suspended particles. The weight of $50 \mathrm{~mL}$ empty density bottle was taken and recorded, $w_{o}$. The density bottle was first filled with water, weighed and recorded, $w_{1}$. An equivalent quantity of oil was replaced with the water in the same bottle and weighed as $w_{2}$. The specific density of the oil was determined as follows;

$$
\text { Specific density }=\frac{w_{1}-w_{0}}{w_{2}-w_{0}}
$$

where;

$$
\begin{aligned}
& w_{0}=\text { Weight of empty density bottle }(\mathrm{g}) . \\
& w_{1}=\text { weight of density bottle filled with water }(\mathrm{g}) . \\
& w_{2}=\text { weight of density bottle filled with oil }(\mathrm{g}) .
\end{aligned}
$$

\subsubsection{Saponification Value}

$2 \mathrm{~g}$ of the oil sample was weighed into a $250 \mathrm{~mL}$ quick fit flask and $25 \mathrm{~mL}$ of 0.5 methanolic $\mathrm{KOH}$ was added. The flask was connected with an air condenser and boiled for 1 hour until all the fat was completely saponified. While the solution was still hot, it was then titrated with $0.5 \mathrm{M} \mathrm{HCl}$ using phenolphthalein indicator to a colourless end point. A blank titration was carried out concurrently. The saponification value $(S V)$ was calculated as;

$$
S V=\frac{(B-S) \times N \times 56.10}{w t}
$$

where;

$$
\begin{aligned}
& S V=\text { Saponification Value }(\mathrm{mg} \mathrm{KOH} / \mathrm{g}) . \\
& S=\text { volume of } \mathrm{HCl} \text { used }(\mathrm{mL}) . \\
& B=\text { volume of } \mathrm{HCl} \text { use for blank }(\mathrm{mL}) . \\
& N=\text { normality of } \mathrm{HCl} . \\
& w t=\text { weight of oil sample }(\mathrm{g}) . \\
& 56.10=\text { Molar mass of } \mathrm{KOH} .
\end{aligned}
$$

\subsubsection{Acid Value}

$3 \mathrm{~g}$ of the oil sample was weigh into a conical flask and 50 mLof absolute alcohol added. This was heated on a water bath at $40^{\circ} \mathrm{C}$ for half an hour to dissolve the oil completely. It was allowed to cool and then titrated against $0.1 \mathrm{M}$ ethanolic $\mathrm{KOH}$ using phenolphthalein indicator until a pink colour which lasted for at least 30 seconds was observed. A blank titration was carried out concurrently. The acid value was then calculated using the expression:

$$
A V=\frac{(a-b) M \times 56.1}{W}
$$

where; 
$A V=$ Acid Value (mg KOH/g).

$a=$ volume of $\mathrm{KOH}$ in $\mathrm{ml}$ for blank.

$b=$ volume of $\mathrm{KOH}$ in $\mathrm{ml}$ for test.

$M=$ molarity of $\mathrm{KOH}$.

$W=$ weight of the oil sample $(\mathrm{g})$.

$56.1=$ molar mass of $\mathrm{KOH}$.

\subsubsection{Iodine Value}

The oil sample $0.2 \mathrm{~g}$ was dissolved in $15 \mathrm{~mL}$ carbon tetrachloride in a conical flask and $25 \mathrm{~mL}$ WIJ'S solution was added and stopper. The content was mixed vigorously and $20 \mathrm{~mL}$ of $10 \%$ potassium iodide solution and $15 \mathrm{~mL}$ water was added. A blank was also prepared concurrently; both were placed in a dark room and allowed to stand for at least $1 \mathrm{hr}$. This was to allow for complete addition reaction between the double bonds of the oil and the liberated iodine to a pale yellow colour. At this point, a few drops of starch indicator solution were added and titrated against standard $0.1 \mathrm{~N}$ Sodium thiosulphate to a blue end point. The iodine value was then calculated as follows;

$$
I V=\frac{M(a-b) \times 126.9 \times \frac{100}{1000}}{W}
$$

where;

IV = Iodine Value.

126.9 = Molar mass of iodine.

$M=$ Molarity of Sodium thiosulphate.

$a=$ Volume $(\mathrm{mL})$ of Sodium thiosulphate used for blank.

$b=$ Volume $(\mathrm{mL})$ of thiosulphate used for the test.

$100 / 1000=$ Multiplication factor as define for iodine value.

$w=$ Weight of oil sample.

\subsubsection{Peroxide Value}

$5 \mathrm{~g}$ of the oil sample was weighed into a $250 \mathrm{~mL}$ round bottom flask containing $20 \mathrm{~mL}$ of the solvent mixture of glacial acetic acid and chloroform $(2: 1 \mathrm{v} / \mathrm{v})$. The content was swelled until the sample dissolved completely and then $0.5 \mathrm{~mL}$ of saturated potassium iodide solution was added followed by stirring with a glass rod for one minute. The resultant homogenous solution was allowed to stand in the dark room for about $1 \mathrm{~min}$ after which $30 \mathrm{~mL}$ of distilled water was added and titrated with standard $0.01 \mathrm{~N} \mathrm{Na}_{2} \mathrm{~S}_{2} \mathrm{O}_{3} \cdot 5 \mathrm{H}_{2} \mathrm{O}$. As soon as the yellow colour turns colourless, starch indicator $0.5 \mathrm{~mL}$ was added and titration continued until the blue colour changed to colourless. A blank titration was also carried out. The peroxide value was calculated by;

$$
P V=\frac{1000 \times\left(v_{1}-v_{2}\right) \times N}{W}
$$

where;

$P V=$ Peroxide value $\left(\mathrm{m}_{\mathrm{eq}} / \mathrm{kg}\right)$. 
$W=$ weight of oil.

$v_{1}=$ volume of $\mathrm{Na}_{2} \mathrm{~S}_{2} \mathrm{O}_{3} \cdot 5 \mathrm{H}_{2} \mathrm{O}$ used for test.

$v_{2}=$ volume of $\mathrm{Na}_{2} \mathrm{~S}_{2} \mathrm{O}_{3} \cdot 5 \mathrm{H}_{2} \mathrm{O}$ used for blank.

$N=$ normality of the $\mathrm{Na}_{2} \mathrm{~S}_{2} \mathrm{O}_{3} \cdot 5 \mathrm{H}_{2} \mathrm{O}$.

\subsubsection{Free Fatty Acid}

$50 \mathrm{~mL}$ of the oil sample was placed in a beaker, neutralized methylated spirit ( 0.1 $\mathrm{M} \mathrm{NaOH}$ was added to methylated spirit to a pink colour and then heated) was added to the oil sample and heated on a hot plate for $1.0 \mathrm{~min}$. Phenolphthalein indicator (3 drops) were added and then titrated against $0.1 \mathrm{~N} \mathrm{HCl}$ vigorously to the appearance of the first permanent pink colour which lasted for at least 30 seconds, with the same intensity as that of the neutralized alcohol before the addition of sample. The \%FFA is calculated as follows;

$$
\% F F A=\frac{\text { Titre value } \times M \times 28.2}{W}
$$

where,

$28.2=$ conversion factor in relation to oleic acid.

$W=$ Weight of sample.

$M=$ Molar concentration of $\mathrm{HCl}$.

\subsubsection{Fatty Acids Composition of the 0il}

The percentage fatty acid composition of the oil was determined using the method adopted by [17]. Fatty acids methyl esters of the oil were prepared by dissolving $0.5 \mathrm{~mL}$ of the oil in $5 \mathrm{~mL}$ hexane, $5 \mathrm{~mL}$ sodium methoxide solution was also added. The mixture was stirred vigorously using a vortex stirrer for 10 seconds. The solution was allowed to stand for 10 minutes to separate out the clear solution of fatty acids methyl esters from the cloudy aqueous layer. The upper layer was then collected carefully into a sample bottle and the fatty acids composition of the oil was determined by injecting its fatty acids methyl esters into a gas chromatographic mass spectrophotometer analyzer according to the conditions prescribed by Hale and Belgin (2011). GC-MS incorporated with an auto sampler and Real Time Analysis software system was used for analyzing FAME. The split ratio was 1:20 and the flow-rate of carrier gas (helium) $2 \mathrm{~mL} / \mathrm{min}$. The injector and detector temperatures were fixed at $250^{\circ} \mathrm{C}$. The temperature programme for the column was: held at $60^{\circ} \mathrm{C}$ for $1 \mathrm{~min}$ and increased by $13^{\circ} \mathrm{C} / \mathrm{min}$ to $175^{\circ} \mathrm{C}$. Thereafter, it was increased at $4^{\circ} \mathrm{C} / \mathrm{min}$ to $215^{\circ} \mathrm{C}$, and then held at $215^{\circ} \mathrm{C}$ for $35 \mathrm{~min}$., the total runs were 86 minutes. The mass spectrometer was operated in EI mode at $70 \mathrm{eV}$ scanning at a range $30-500 \mathrm{~m} / \mathrm{z}$ in a $1 \mathrm{~s}$ cycle, in a full scan acquisition mode. Comparing with the MS self-contained chromato-gram library, the species of every group were identified, and the relative proportion of each species (\%) was obtained by dividing the individual peak area with the total peaks areas.

\subsection{Soap Formulation}

The soap was formulated according to the method prescribed by [18]. $100 \mathrm{~g}$ of 
Balanites aegyptiaca seed kernel oil was weighed into a $500 \mathrm{~mL}$ beaker and heated to $100^{\circ} \mathrm{C} .20 \mathrm{~mL}$ of $60 \% \mathrm{NaOH}$ solution was gradually added while stirring until complete saponification was achieved. The soap paste was then transferred into a cast and allowed for complete drying.

\subsubsection{Performance Evaluation of Soap}

The performance evaluation test of the soap was carried out by the blender method of determining foam volume, density, stability and lubricity [19]. The soap solution $10 \%$ was prepared and transferred into a blender and agitated for 10 seconds at medium speed. The foam generated was then transferred into a calibrated measuring cylinder and a rubber stopper which is slightly smaller than the diameter of the measuring cylinder was gently dropped into the foam. The time for the rubber stopper to pass between two points $(100$ and $80 \mathrm{~mL}$ ) was measured. The rate at which the stopper falls was dependent on the upward pressure and this upward pressure is inversely proportional to the size of the bubbles. It implies that the denser the foam, the slower the fall of the rubber stopper.

\subsubsection{Total Fatty Matter (TFM)}

The method described by [18] was used. The total fatty matter test was carried out by reacting soap with acid in the presence of hot water and measuring the fatty acids obtained. $10 \mathrm{~g}$ of finished soap was weighed and $150 \mathrm{~mL}$ distilled water was added and heated. The soap was dissolved in $20 \mathrm{~mL}$ of $15 \% \mathrm{H}_{2} \mathrm{SO}_{4}$ while heating until a clear solution was obtained. Fatty acids on the surface of the resulting solution was solidified by adding $7 \mathrm{~g}$ of bee wax and reheated. The set up was allowed to cool to form cake which was removed and blotted to dryness and the total fatty matter was obtained as follows;

$$
\% \text { TFM }=\frac{(A-X) \times 100}{W}
$$

where;

$$
\begin{aligned}
& A=\text { weight of wax }+ \text { oil. } \\
& X=\text { weight of wax. } \\
& W=\text { weight of soap. }
\end{aligned}
$$

\subsubsection{Total Alkali}

The total alkali was determined by titrating excess acid contained in the aqueous phase with standard volumetric $\mathrm{NaOH}$ solution [20]. $10 \mathrm{~g}$ of the finished soap was weighed and $100 \mathrm{~mL}$ of neutralized alcohol was added to it, $5 \mathrm{~mL}$ of $1 \mathrm{~N}$ $\mathrm{H}_{2} \mathrm{SO}_{4}$ solution was added to the mixture and heated till the soap sample dissolved. The test solution was titrated against $1 \mathrm{~N} \mathrm{NaOH}$ using phenolphthalein as indicator. The total alkali was obtained using the formula;

$$
\% \text { Total alkali }=\frac{V_{A}-V_{B} \times 3.1}{W}
$$

where: 
$V A=$ Volume of acid.

$V B=$ Volume of base.

$W=$ weight of soap.

3.1 = milliequivalent of $\mathrm{Na}_{2} \mathrm{O}$.

\subsubsection{Free Caustic Alkali}

A method prescribed by [21] and modified by [18] was used. $5 \mathrm{~g}$ of the finished soap was weighed and dissolved in $30 \mathrm{~mL}$ of ethanol. Few drops of phenolphthalein indicator were added and $10 \mathrm{ml}$ of $20 \% \mathrm{BaCl}_{2}$ was also added. The resulting solution was titrated against $0.05 \mathrm{M} \mathrm{H}_{2} \mathrm{SO}_{4}$. Free caustic alkali was calculated as follows;

$$
\mathrm{NaOH}=\frac{3.1 \times V_{A}}{W}
$$

where;

$$
\begin{aligned}
& V_{A}=\text { Volume of acid. } \\
& W=\text { weight of soap. } \\
& 3.1=\text { milliequivalent of } \mathrm{Na}_{2} \mathrm{O} .
\end{aligned}
$$

\subsubsection{Moisture Content of Soap}

$5 \mathrm{~g}$ of each sample was accurately weighed using analytical balance (sensitivity $0.1 \mathrm{mg}$ ) into dried, tarred moisture dish and dried in an oven (Memmert, Germany) for 2 hours at $110^{\circ} \mathrm{C}$ and repeated until a constant weight (difference between two measurements not exceeding $0.5 \mathrm{mg} / \mathrm{g}$ of sample) was reached. The percent moisture was then calculated using method adopted by [21].

$$
\% \text { Moisture }=\frac{C_{s}-C_{h} \times 100}{C_{s}-C_{w}}
$$

where;

$C_{w}=$ weight of crucible.

$C_{s}=$ weight of crucible + sample.

$C_{h}=$ weight of crucible + sample after heating.

\subsubsection{Soap pH}

$10 \mathrm{~g}$ of powdered soap was weighed and dissolved in distilled water in a $100 \mathrm{~mL}$ volumetric flask. This was made up to the make to prepare $10 \%$ soap solution. The $\mathrm{pH}$ of the $10 \%$ soap solution was determined using a $\mathrm{pH}$ meter.

\subsection{Lotion Formulation}

The lotion was formulated according to the method prescribed by [22]. In this formulation, $80 \mathrm{~g}$ of water was transferred into a beaker. $14 \mathrm{~g}$ of Balanites aegyptiaca seed kernel oil was also transferred into a separate beaker and $4 \mathrm{~g}$ of E-wax emulsifier was added into the oil. The mixture was placed on the hot plate and heated to $120^{\circ} \mathrm{C}$ holding for 15 minutes. The beaker containing distilled water was placed on a separate hot plate and heated to $100^{\circ} \mathrm{C}$ holding for 13 minutes. The mixture of hot oil and emulsifier was transferred into a plastic bowl which 
was placed in cold water and immediately the hot water was slowly added while still blending. Blending was continued until mixture thickens, addition of other additives followed as desired when the temperature of the mixture was about $50^{\circ} \mathrm{C}$ or below.

\subsubsection{Creaming Index (CI)}

The dispersed phase (of an oil-in-water emulsion) has a tendency to separate and rise to the top of the emulsion forming a layer of oil droplets. This phenomenon is called creaming. Creaming is one of the first signs of impending emulsion instability and should be taken seriously. A good test method to predict creaming is centrifugation. The lotion was heated to $50^{\circ} \mathrm{C}$ and centrifuged for thirty minutes at $3000 \mathrm{rpm}$. The resultant product was inspected for signs of separation.

\subsubsection{Effect of Temperature on Lotion Stability}

The lotions, experimental and control were placed in the refrigerator at $-10^{\circ} \mathrm{C}$ for 24 hours for the minimum temperature. It was removed, kept at room temperature for 24 hours then analyzed. For maximum temperature, the product was placed in the oven at $45^{\circ} \mathrm{C}$ for 24 hours, removed and also kept at room temperature for 24 hours then analyzed for colour, odour, $\mathrm{PH}$, viscosity, texture and signs of separation.

\subsubsection{Effect of Light Exposure on Lotion Stability}

The products both neat and one with additives were exposed to sunlight for 8 hours and the analysis for any change in colour, odour, $\mathrm{pH}$, viscosity, texture and signs of separation were carried out.

\section{Results and Discussion}

The results of physicochemical characteristics of the seed kernel oil of Balanites aegyptiaca are summarized in Table 1 . The oil yield was found to be $45.32 \%$ and is within the range of $45 \%$ - $46 \%$ reported [23]. This indicates that the processing of the oil for industrial or edible would be economical feasible.

The moisture content of the seed kernel oil of Balanites aegyptiaca was $0.114 \%$ $\pm 0.04 \%$ while the specific gravity was $0.90 \pm 0.00$ and these low values guaranteed the stability of the oil [24]. The observed low moisture content serve as an indication that the activities of the micro-organisms would be reduced and thereby increases the shelf life of Balanites aegyptiaca seed [25]. The viscosity and refractive index of the oil are $0.92 \mathrm{cp}$ and 1.45 respectively. The refractive index was in close agreement with the values of most crude vegetable oils and fats shown in Table 2.

The saponification value of the oil is $200.02 \pm 0.12168 .67 \mathrm{mg} \mathrm{KOH} / \mathrm{g}$ which is comparable to the values of certain vegetable oils like; sesame, neem, groundnut, palm fruit and soya beans, while iodine value $(104.39 \pm 0.00)$ in the present work is within the range for sesame seed (Table 2). The saponification value of oil serves as an important parameter in determining the suitability of the oil for 
Table 1. Physicochemical characteristics of Balanites aegyptiaca oil.

\begin{tabular}{cc}
\hline Parameter & Desert date \\
\hline Oil yield (\%) & $45.32 \pm 0.0026$ \\
Moisture content (\%) & $0.114 \pm 0.04$ \\
Viscosity (cp) & 0.92 \\
Specific gravity & $0.90 \pm 0.03$ \\
Refractive index & 1.45 \\
Saponification value (mg KOH/g) & $200.02 \pm 0.12$ \\
Peroxide value (m Eq/kg) & $2.95 \pm 0.00$ \\
Acid value (mg KOH/g) & $2.14 \pm 0.28$ \\
Iodine value $100 / \mathrm{g}$ & $104.39 \pm 0.00$ \\
Free fatty acid $(\%)$ & $0.82 \pm 0.01$ \\
\hline
\end{tabular}

Table 2. Analytical properties of some crude vegetable oils and fats used for the manufacture of liquid soap and shampoo.

\begin{tabular}{cccc}
\hline Oils/Fats & Refractive index & Saponification value & Iodine value \\
\hline Sesame seed & $1.465-1.469$ & $167-195$ & $104-120$ \\
Neem & 1.465 & 194.5 & 71 \\
Groundnut & $1.460-1.465$ & $187-196$ & $80-106$ \\
Palm kernel & $1.460-1.472$ & $230-254$ & $14.5-19$ \\
Castor bean & $1.466-1.473$ & $176-187$ & $81-91$ \\
Mustard seed & $1.461-1.469$ & $170-184$ & $92-125$ \\
Bone tallow & $1.456-1.457$ & $189-200$ & $31-38$ \\
Coconut & $1.448-1.450$ & $248-265$ & 6.11 \\
Olive & $1.467-1.471$ & $184-196$ & - \\
Soya bean & $1.467-1.470$ & $188-195$ & $120-143$ \\
Palm fruit & $1.449-1.455$ & $190-209$ & $50-55$ \\
Babassis kernel & $1.448-1.457$ & $245-256$ & $10-18$ \\
Present studies & 1.45 & $200.02 \pm 0.12$ & $104.39 \pm 0.00$ \\
\hline
\end{tabular}

Source: Manji et al. (2013), [23].

soap making. Iodine value is the measure of the degree of the unsaturation of the oil. Higher Iodine value indicates higher unsaturation of fats and oils. Oils having iodine value below 100 are non-drying, those having values between 100 130 are semi-drying while those having values above 130 are termed drying oils [26].

The Free fatty acids (FFA), acid value and peroxide values are important parameters in evaluating the quality of fats and oils with respect to rancidity and oxidation. The acid value of Balanites aegyptiaca seed kernel oil was $2.14 \pm 0.28$ $\mathrm{mg} \mathrm{KOH} / \mathrm{g}$ while free fatty acids value was $0.82 \pm 0.01 \mathrm{mg} \mathrm{KOH} / \mathrm{g}$. Acid value 
was determined to quantify the fatty acid found in the oil as it measures the free fatty acids of oil. The acid value was low $(2.14 \pm 0.28 \mathrm{mg} \mathrm{KOH} / \mathrm{g})$ and this shows that this oil is stable [25]. Oils with high acid value, which will also mean high $\%$ FFA will undergo rancidity due to the hydrolysis of the free fatty acids on storage. The acid value and \% FFA of Balanites aegyptiaca seed kernel oil are lower than FAO/WHO standard for edible oils [26]. The low \%FFA reduces the tendency of the oil to undergo hydrolytic activities. In most oils, the level of free fatty acid which causes deterioration is noticed when the \%FFA calculated as oleic acid falls within the range of $0.5 \%-1.5 \%$ [23].

Peroxide value is used as a measure of the extent to which rancidity reactions have occurred during storage it could be used as an indication of the quality and stability of fats and oils. The peroxide value determined for the seed kernel oil of Balanites aegyptiaca is $2.95 \mathrm{mEq} / \mathrm{g}$ and was lower than FAO/WHO standard. A low peroxide value as seen in our study increases the suitability of the oil for a long storage due to low level of oxidative and lipolytic activities [27].

The composition of the fatty acid content of the seed kernel oil of Balanites aegyptiaca is shown in Table 3 . The oil mainly contained saturated fatty acids (36.48\%) and monounsaturated fatty acids (30.25\%) and a low amount of polyunsaturated fatty acids (19.20\%). The most abundant fatty acids of Balanites aegyptiaca seed oil were oleic (28.32\%) and palmitic (20.51\%) acids followed by linoleic (19.20\%), stearic (15.97\%) acids and palmitoleic (1.93\%) acid, which together comprised $85.93 \%$ of the total fatty acid. The fatty acid composition of the seed oil is similar to the values reported by [28].

The quality assessment of the soap formulated from the seed kernel oil of $\mathrm{Ba}$ lanites aegyptiaca are shown in Table 4 . The soap tends to have good leathering, stable foam, small foam size and a creaming feeling when used to wash hands.

The physicochemical properties of the soap are summarized Table 5. These include the percent total fatty matter, percent total alkali, percent free caustic alkali, percent moisture content and the $\mathrm{pH}$. There was no any reasonable change between soap A which was without any additives and soap B were colour, perfume and preservatives where added. The result was also comparable with two other common soaps found in the market (Standard 1 and 2).

The moisture content is a parameter that is used in assessing the shelf-life of a product. The moisture content of $11.85 \%$ recorded for the soap is within the

Table 3. Fatty acid content of the seed kernel oil of Balanites aegyptiaca.

\begin{tabular}{cccc}
\hline Peak No & Fatty acid esters & $\begin{array}{c}\text { Percent } \\
\text { composition }\end{array}$ & Proposed fatty acid esters \\
\hline 11 & Palmitic Acid Methyl Ester & 20.51 & C16 Saturated fatty acid \\
12 & Linoleic Acid Methyl Ester & 19.20 & C18 Polyunsaturated fatty acid \\
13 & Oleic Acid Methyl Ester & 28.32 & C19 Monounsaturated fatty acid \\
14 & Stearic Acid Methyl Ester & 15.97 & C18 Saturated fatty acid \\
16 & Palmitoleic Acid Methyl Ester & 1.93 & C17 Monounsaturated fatty acid \\
\hline
\end{tabular}


Table 4. Quality evaluation of the soap.

\begin{tabular}{ccc}
\hline Parameter & $\begin{array}{c}\text { Soap A } \\
\text { (without additives) }\end{array}$ & $\begin{array}{c}\text { Soap B } \\
\text { (with additives) }\end{array}$ \\
\hline Foam size & Small and think & Small and think \\
Lather texture & Creaming & Creaming \\
Colour & White & White \\
Foam stability & Stable & Stable \\
Leathering & Good & Good \\
\hline
\end{tabular}

Table 5. Physicochemical analysis of the soap.

\begin{tabular}{ccccc}
\hline \multirow{2}{*}{ Parameters } & \multicolumn{2}{c}{ Soaps } & \multicolumn{2}{c}{ Standard } \\
\cline { 2 - 5 } & A & B & 1 & 2 \\
\hline \%Total Fatty Matter & $65.68 \pm 0.7$ & $65.68 \pm 0.07$ & $67.00 \pm 0.15$ & $62.25 \pm 0.02$ \\
\%Total Alkali & $0.22 \pm 0.02$ & $0.22 \pm 0.04$ & $0.46 \pm 0.02$ & $1.05 \pm 0.02$ \\
\%Free Caustic Alkali & $0.08 \pm 0.02$ & $0.08 \pm 0.02$ & $0.17 \pm 0.01$ & $0.38 \pm 0.02$ \\
\%Moisture & $11.85 \pm 0.4$ & $11.85 \pm 0.2$ & $8.25 \pm 0.03$ & $15.46 \pm 0.03$ \\
Content & & & & \\
pH & $8.37 \pm 0.1$ & $8.27 \pm 0.05$ & $6.20 \pm 0.006$ & $5.80 \pm 0.005$ \\
\hline
\end{tabular}

recommended percentage $10 \%-15 \%$ [29]. The implication of high moisture content in soap is that the excess water could possibly react with any unsaponified neutral fat to give free fatty acid and glycerol in a process called hydrolysis of soap on storage [30].

The total fatty matter (TFM) of soap is a measure of its suitability for bathing or launderings purpose. The minimum recommended values are $20.0 \%$ and $50.0 \%$ for laundry and toilet soaps respectively. The value obtained for the soap, which is $65.68 \%$, indicated that this soap will be most suitable for bathing rather than for laundry due to its high total fatty matter. In addition, the British Industrial Standard (BIS) norms reveal that such soaps can be categorized as Grade III Soap and are used for general bathing purpose.

Onyekwere (1996) reported that the free caustic alkali content is one of the parameters that determine the abrasiveness of any given soap [31]. This mostly results from improper or incomplete saponification. The recommended value is $0.25 \%$ for laundry soap and $0.2 \%$ for toilet soap [32]. The value of the free caustic alkali recorded for this soap is $0.08 \%$, this is very low indicating that it was highly saponified.

The $\mathrm{pH}$ of the soap was determined to be between $8.27 \pm 0.05$ to $8.37 \pm 0.1$ which places the soap as a moderately basic soap. High alkalinity in soap could pre-expose the skin to various diseases because of the saponification of the fats and oils on the skin during bathing, producing a soluble organic salt which will be washed away by the bath water.

The stability test of the lotion formulated from the seed kernel oil of Balanites aegyptiaca are presented in Table 6 and Table 7. There was no significant 
Table 6. Lotion stability test A.

\begin{tabular}{ccccccc}
\hline \multirow{2}{*}{ Parameter } & \multicolumn{2}{c}{ Temperature } & & LE & CI & Control \\
\cline { 2 - 3 } & Low & High & & & \\
\hline Colour & Cream & Cream & Cream & Cream & Cream \\
Odour & Neutral & Neutral & Neutral & Neutral & Neutral \\
$\mathrm{P}^{\mathrm{H}}$ & 5.49 & 5.44 & 5.3 & 5.44 & 3.8 \\
Viscosity & 34 & 33 & & 31 & 31 & 33 \\
Texture & Smooth & Smooth & Smooth & Smooth & Smooth \\
Sign of Separation & None & Mild & None & Mild & None \\
\hline
\end{tabular}

Note: LE-light exposure, CI-creaming index.

Table 7. Lotion stability test B.

\begin{tabular}{|c|c|c|c|c|c|}
\hline \multirow{2}{*}{ Parameter } & \multicolumn{2}{|c|}{ Temperature } & \multirow{2}{*}{ LE } & \multirow{2}{*}{$\mathrm{CI}$} & \multirow{2}{*}{ Control } \\
\hline & Low & High & & & \\
\hline Colour & Pink & Pink & Pink & Pink & Pink \\
\hline Odour & Perfumed & Perfumed & Perfumed & Perfumed & Perfumed \\
\hline $\mathrm{pH}$ & 5.4 & 5.1 & 5.3 & 5.1 & 5.4 \\
\hline Viscosity & 34 & 33 & 31 & 31 & 34 \\
\hline Texture & Smooth & Smooth & Smooth & Smooth & Smooth \\
\hline Sign of Separation & None & Mild & None & Mild & None \\
\hline
\end{tabular}

variation of the results of lotion A without any additives and lotion B were perfume, colour and preservatives where added except for the $\mathrm{pH}$. The $\mathrm{pH}$ of lotion A (control without additives) and was left on the bench tends to decrease, the lotion became more acidic, growth of microorganisms was also observed on the control. The $\mathrm{pH}$ of the emulsion formulated is between 5.09 to 5.26 , which is close to the $\mathrm{pH}$ of the mantle of the skin of 5.5 showing that it will be more skin compatible [33].

\section{Conclusion}

The present study on the physicochemical properties, formulation of soap and lotion from Balanites aegyptiaca seeds suggests that the seed of this plant has high oil content as was revealed by the $\%$ yield $(45.32 \% \pm 0.0026 \%)$. Thus it can be a good source of raw material for many oil based products (soap, shampoo, bio-diesel, lubricants, etc.). The soap and body lotion formulated from the oil of these seeds has good property and therefore can be applicable in the soap and cosmetic industry. The seed oil is stable and similar to the palm oil and it can also be a sustainable alternative to palm oil in food industries.

\section{Conflicts of Interest}

The authors declare no conflicts of interest regarding the publication of this paper. 


\section{References}

[1] Elseed, A.M.A.F., Amin, A.E., Khadija, A.A., Ali, J.S. Hishinum, M. and Henana, K. (2002) Nutritive Evaluation of Some Fielder Tree Species during the Dry Season in Central Sudan. Asian Aust. Journal Animal Science, 15, 844-850.

[2] Guinand, Y. and Lemessa, D. (2001) Wild Food Plants in Ethiopia: Reflections on the Role of Wild Foods and Famine Foods at a Time of Drought. In: Kenyatta, C. and Henderson, A., Eds., The Potential of Indigenous Wild Foods. Workshop Proceedings, USAID/OFDA, Mombassa, Kenya.

[3] Adebayo, S.E., Orhevba, B.A., Adeoye, P.A., Fase, O.J. and Musa, J.J. (2012) Solvent Extraction and Characterizaion of oil from African Star Apple (Chrysophyllum albidum) Seeds. International Journal of Academic Research, 3, 178-183.

[4] Vonmaydell, H.J. (1986) Trees and Shrubs of the Sahel: Their Characteristics and Uses. Eschborn, GTZ, Germany, 525.

[5] Author, C.C. (1995) Lipid-Based Fats Substitutes. Critical Review Science Nutrients Journal, 35, 4-5.

[6] Feranil, A.B., Dauzo, P.L., Kuzawa, C.W. and Adair, L.S. (2011) Coconut Oil Predicts a Beneficial Lipid Profile in Pr-Menopausal Women in the Philippines. Asian pacific Journal of clinical Nutrition, 20, 190-195.

[7] Oxford University Press (2005) Oxford English Dictionary. 3rd Edition, Oxford University Press, Oxford.

[8] Elham, T. (2008) Effect of $\alpha$-Toropherol on Oxidative Stability and Phytosterol Oxidation during Heating of Some Regular and High Oleic Vegetable Oils. Journal of Oil and Fat Industries, 85, 857-867.

[9] Murwan, K., Sabah, E.L.-K. and Abdelsalam, A.A. (2012) The Compositional Quality of Six Refined Edible Oils in Khartown State, Sudan. ARPN Journal of Science and Technology, 2, 177-180.

[10] O’Brien, R.D., Walter, E.F. and Wan, P.J. (2000) Introduction to Fats and Oils Technology. 2nd Edition, AOCS Press, Champaign Illinois, 335-340.

[11] McNaugh, A.D. and Wilkinson, A. (1997) Soaps: IUPAC Compendium of Chemical Terminology. 2nd Edition, Blackwell Scientific Publications, Oxford.

[12] Miller, S. (1994) The Natural Soap Book. Storey Publishing, North Adams, 45-50.

[13] Viorica, P., Alina, S. and Simona, D. (2011) Quality Control and Evaluation of Certain Properties for Soap Made in Romania. Journal of Scientific Study and Research Chemistry and Chemical Engineering, Biotechnology, Food Industry, 12, 257-261.

[14] Remington, J.P. (2006) The Science and Practice of Pharmacy. 21st Edition, Lippincott Williams and Wilkins, Philadelphia, 772.

[15] ASTM (2008) Standard Specification for Biodiesel Fuel (B100) Blend Stock for Distillate Fuels. In: Annual Book of ASTM Standards, ASTM International, West Conshohocken, Method D6751-08; Alcoholysis for Biodiesel Fuel Production and Application of the Reaction to Oil Processing. Journal of Molecular Catalysis B: Enzymatic, 76, 133-142.

[16] Cocks, L.V. and VanRede, C. (1997) Laboratory Handbook for Oil and Fats Analysis. Academia Press, London, 67.

[17] Eqbal, M.A.D., Halimah, A.S., Abdulah, M.K. and Zalifah, M.K. (2011) Fatty Acids Composition of Four Different Vegetable Oils (Red Palm Olein, Corn Oil and Coconut Oil) by GC. In: 2nd International Conference on Chemistry and Chemical Engineering, IACSIT Press, Singapore, 31-34. 
[18] Mak-Mensah, E.E. and Firempong, C.K. (2011) Chemical Characteristics of Toilet Soap Prepared from Neem-Pelagia. Asian Journal of Plant Science Research, 1, 1-7.

[19] http://www.scientificspectator.com/documents/suggested\%20reading/KLEIN\%20O N\%20EVALUATING\%20FOAM.pdf

[20] http://www.lipidhome.co.uk

[21] Milwidsky, B.M. and Gabriel, D.M. (1994) Detergent Analysis: A Handbook of Cost Effective Quality Control. Micele Press, 160-161.

[22] Romanowski, P. (2011) Stability Testing of Cosmetics and Pharmaceutical Products. http://chemistscorner.com/perry-romanowski/

[23] Manji, A.J., Sarah, E.E. and Modibo, U.U. (2013) Studies on the Potentials of Balanites aegyptiaca Seed Oil as a Raw Material for the Production of Liquid Cleansing Agents. International Journal of Physical Science, 8, 1655-1660.

[24] Sirelkhatim, B.E., Asha, M.E., Nourelhuda, A.K., Adil, A.G. and Hayat, O.D. (2014) A Review of Omega-3 and Omega-6 Essential Fatty Acids: Uses, Benefits and Their Availability in Pumpkins (Cucuibita maxima) and Seed and Desert Dates (Balanites aegytiaca) Seed Kernel Oils. Pakistan Journal of Biological Sciences, 17, 1195-1208. https://doi.org/10.3923/pjbs.2014.1195.1208

[25] Haftu, G.A. (2015) Physico-Chemical Characterization and Extraction of Oil from Balanites aegyptiaca Plant (Seed). World Journal of Pharmaceutical Research, 4, $1723-1732$.

[26] Adegbe, A.A., Larayetan, R.A. and Omojuwa, T.J. (2016) Proximate Analysis, Physicochemical Properties and Chemical Constituents Characterization of Moringa oleifera (Moringaceae) Seed Oil Using GC-MS Analysis. American Journal of Chemistry, 6, 23-28.

[27] Asuquo, J.E. (2008) Studies on the Adsorption of Some Selected Metallic Soaps onto Hematite. PhD Dissertation, University of Port Harcourt, Port Harcourt.

[28] Judicael, T.Q., Patrice, B., Adjima, B., Nebpawinde, K., Anne, M.L., Amade, O. and Imael, H.N.B. (2017) Chemical Composition, Physicochemical Characteristics, and Nutritional Value of Lannea kerstingii Seeds and Seed Oil. Journal of Analytical Methods in Chemistry, 2017, Article ID: 2840718.

[29] (2007) Encyclopedia of Industrial Chemical Analysis. Interscience Publishers Division of John Wiley \& Sons, 179-180.

[30] Tewari, K.S. (2004) Quality Assessment of Soaps. A Textbook of Chemistry. 3rd Edition, Vikas Publishing House PVT Ltd., 26, 594-600.

[31] Onyekwere, C. (1996) Cassava Peels Ash. An Alternative Source of Alkali in Soap Production. Thesis of Chemical Engineering, University of Port Harcourt, Port Harcourt, 1-33.

[32] Schuman, K. and Siekman, K. (2005) Soaps in Ullmann's Encyclopedia of Industrial Chemicals.

[33] Oyedeji, F.O. and Okeke, I.T. (2010) Comparative Analysis of Moisturing Creams from Vegetable Oils and Paraffin Oils. Journal of Applied Sciences Research, 5, 157-160. https://doi.org/10.3923/rjasci.2010.157.160 